\title{
Dependence symptoms in young cannabis users? A prospective epidemiological study
}

Agnes Nocon ${ }^{\mathrm{a},{ }^{*}}$, Hans-Ulrich Wittchen ${ }^{\mathrm{a}, \mathrm{b}}$, Hildegard Pfister ${ }^{\mathrm{a}}$, Petra Zimmermann ${ }^{\mathrm{b}}$, Roselind Lieb $^{\text {a }}$

a Max-Planck-Institute of Psychiatry, Clinical Psychology and Epidemiology, Kraepelinstrasse 2-10, 80804 Munich, Germany

b Institute of Clinical Psychology and Psychotherapy, Technical University of Dresden, Chemnitzer

Strasse 46, 01187 Dresden, Germany

\begin{abstract}
Aim: To examine prospectively over a period of 4 years the profile of cannabis dependence and the risk of specific dependence criteria in a community sample of adolescents.

Methods: A representative community sample of 2446 young adults aged 14-24 years at baseline was followed up over a period of 4 years. Frequency of use measures and of criteria for DSM-IV dependence were assessed by standardized diagnostic interview measures (CIDI). To explore the nature of this association, frequency of use and concomitant use of other psychoactive substances was considered.

Results: $30 \%$ of the sample were cannabis users. Among all users $35 \%$ met at least one dependence criterion. Most frequently reported dependence criteria among all users were withdrawal (17\%), tolerance (15\%), loss of control (14\%) and continued use despite a health problem (13\%). Even without concomitant use of other illicit drugs, $22 \%$ of low frequency users and $81 \%$ of high frequency users met at least one dependence criterion. Symptom patterns were similar in high and low frequency users. The occurrence of a dependence syndrome or of specific dependence criteria could not be attributed to the use of other illicit drugs or to comorbid nicotine and alcohol dependence.

Conclusions: Regular cannabis use in adolescence is associated with the development of a dependence syndrome. This association cannot be explained by the concomitant use of other illicit substances or by comorbid nicotine and alcohol dependence.
\end{abstract}

Keywords: Cannabis dependence; Symptom profile; Withdrawal; Illicit drug use; Adolescents and young adults; General population

\section{Introduction}

Cannabis is the most prevalent illicit substance used in many western countries (American Psychiatric Association, 1994) such as the US, Australia, New Zealand and most European countries (European Monitoring Centre for Drugs and Drug Addiction (EBDDA), 2003), with an estimated lifetime use rate of $20-46 \%$ in the general population (Anthony et al., 1994; Australian Institute of Health and Welfare, 1999; European Monitoring Centre for Drugs and Drug Addiction (EBDDA), 2003) and even higher rates among adolescents and young adults (37-69\%) (Sydow et al., 2001; Anthony et al., 1994; Coffey et al., 2002; Fergusson and Horwood, 2000; Poulton et al., 1997; Young et al., 2002). Some researchers claim that in this age group cannabis use can already be regarded a 'normal' experience (Fergusson and Horwood, 2000). First use typically occurs in early adolescence and peak use in mid- to late adolescence and young adulthood (Hall and Solowij, 1998; Sydow et al., 2001; Young et al., 
2002) with some indications that the first use of cannabis has shifted to an earlier age (Dennis et al., 2002; Sydow et al., 2001; Degenhardt et al., 2000; Muller and Gmel, 2002).

Fairly consistently across studies it has been estimated that approximately $10 \%$ of US individuals who ever used cannabis become daily users (Anthony et al., 1994), that younger users more probably become daily users (Anthony et al., 1994; Zoccolillo et al., 1999), that frequency of use and early onset are associated with increased risk for developing a dependence syndrome (Coffey et al., 2003; Hall et al., 1994; Sydow et al., 2002; Poulton et al., 1997) and that dependent cannabis use appears to be fairly stable over longer periods of time (Swift et al., 2000; Wittchen et al., 1998a).

Lifetime prevalence rates for cannabis dependence in the US have been estimated to be $4 \%$ (Anthony and Helzer, 1991; Anthony et al., 1994). Higher prevalence rates have been reported from samples of adolescents and young adults in the US and New Zealand (5-9\%, (Anthony et al., 1994; Fergusson and Horwood, 2000; Young et al., 2002). Recent data from various EU countries suggest, however, considerably lower rates (subjects up to age 65: 0.6$1.0 \%$, Wittchen, 2000; de Graaf, 2004; subjects up to the age of 25 years; 1.4-2.3\%; Wittchen and Jacobi, 2004; Perkonigg et al., 1997).

Except for several studies in highly selective clinical drug users samples (e.g. Winters et al., 1999; Chung et al., 2003; Crowley et al., 1998) little attention, however, has been paid to the symptom profile of cannabis dependence in community samples. Anthony and Trinkoff (1989) summarized that daily cannabis users most frequently reported 'psychological problems attributed to drug use' and 'need for larger amounts' (both 21\%) as the most frequent symptoms: Among non-daily users 'psychological problems attributed to drug use' was considerably less frequent (10\%); 'social problems attributed to drug use' was the next most frequently reported item (4\%). Swift et al. (2001) presented rates of 12-month DSM-IV cannabis dependence criteria from the Australian adult population: 'persistent desire/unsuccessful efforts to control use' (37\%) and 'withdrawal/withdrawal relief' (30\%) were the most frequent criteria among cannabis users. Among dependent users the frequency of these criteria was much higher ( $87 \%$ 'desire to control use' and $89 \%$ 'withdrawal') as compared to non-dependent cannabis users (23\% 'desire to control use' and $14 \%$ 'withdrawal'). Coffey et al. (2002) reported for a sample of the 20-21 year old Australians 'persistent desire to control use' as the most frequent 12-month criterion in cannabis users (10\%), followed by 'unintentional use' (8\%). Young et al. (2002) interviewed 12-18 year old adolescents in the USA. In their sample, 'continued use despite physical or psychological problems' ( $42 \%$ of the boys and $48 \%$ of the girls) and 'tolerance' (36\% of the boys and $33 \%$ of the girls) were the most frequent. Dennis et al. (2002) reported as the most frequent 12month DSM-IV cannabis dependence criteria across all age groups (a) 'spending a great deal of time getting, using or getting over effects of cannabis' (54\% of the $12-17$ years old users, $49 \%$ of the $18-25$ years old users, $32 \%$ of the over 25 years old users, $42 \%$ of all users) and (b) 'tolerance' (39\% of the 18-25 years old users, $26 \%$ of the over 25 years old users, $33 \%$ of all cannabis users); in the youngest age group, however, 'used cannabis more often or in larger amounts than intended' was found to be the second most frequently mentioned symptom $(48 \%)$.

To summarize, the available studies of symptoms of dependence among cannabis users indicate some variability in findings. Part of this variation seems to be related to frequency of use and design effects, such as age composition of the studied sample. Further it is noteworthy, that the available epidemiological studies have not yet demonstrated that dependence symptoms and withdrawal as the core symptom can be directly related to the use 
of cannabis, respectively, the frequency and duration of use. An alternative explanation for the existence of dependence symptoms among cannabis users could be that the emergence of such symptoms is due to the concomitant use of other drugs, such as nicotine, alcohol or other psychoactive substances. This alternative hypothesis and explanation remains poorly studied as well.

\section{Aims}

To examine the symptom profile of cannabis dependence prospectively in a large community sample of adolescents and young adults and to examine the following questions:

1. How frequent are DSM-IV dependence symptoms among low frequency (LFU) and high frequency (HFU) cannabis users?

2. Which dependence symptoms are specific for users meeting DSM-IV criteria for cannabis dependence?

3. To what degree are dependence symptoms in cannabis users attributable to the concomitant use of other illicit and licit (alcohol and nicotine) drugs?

\section{Method}

The Early Developmental Stages of Psychopathology Study explores the prevalence, incidence, comorbidity, risk factors, protective factors and 4-year course of mental disorders, with specific emphasis on substance-use disorders in a representative general population sample (Lieb et al., 2000; Wittchen et al., 1998a,d; Perkonigg et al., 1997, 1999; Sydow et al., 2001, 2002). The study is based on three waves, the first conducted in 1995 (t0), the second in 1996-1997 (t1: only the younger cohort was assessed), and the third in 1998-1999 (t2: again with the total sample).

\subsection{Baseline sample and follow-up investigations}

The sample was randomly drawn from the 1994 government registries of residents in metropolitan Munich. A total of 3021 participants aged 14-24 years (birth cohorts 19701981) were successfully interviewed at baseline, resulting in a response rate of $71 \%$. Since the study was designed with a special interest in early stages of substance use disorders, 14-15 year olds were sampled at twice the probability of 16-21 year olds, and 22-24 year olds were sampled at half the probability. For youth under 18 years parents gave their signed permission to participate in the study. At baseline, almost three-quarters of the participants were students, $36 \%$ at the secondary level and $26 \%$ at the university level, and $20 \%$ of the participants were employed. $62 \%$ were living with their parents, $23 \%$ alone, and $12 \%$ with their partners/spouses. The majority of the respondents (59\%) were classified as middle class, reflecting the population of Munich. To account for different sampling probabilities for the different age groups, as well as for noncontact and non-response, the data were adjusted by age, sex and geographic location at baseline, in order to match the distribution of the original sampling frame. Detailed descriptions of the sampling procedures of the baseline investigation and reasons for non-response have already been presented elsewhere (Wittchen et al., 1998c,d).

The follow-up investigations covered an overall period of 42 months (range: $34-50$ months). As emphasis was laid on early stages of substance abuse patterns, the first follow-up (t1; conducted in 1996/1997) was confined to the younger sub-sample (aged 14-17 years at baseline), with a response rate of $88 \%(\mathrm{~N}=1228)$. The second follow-up (t2) included all 
baseline respondents and was conducted in 1998-1999; the response rate was $84 \%(\mathrm{~N}=$ 2548). Of these, 102 participants did not want to respond to questions about illicit drug use at either $\mathrm{t} 0, \mathrm{t} 1$ or $\mathrm{t} 2$. In order to use data from all three assessments in this paper, the analysis are based on the results of $\mathrm{N}=2446$ subjects with complete information at second follow-up: 1101 participants in the younger cohort (aged 14-17 years at baseline, born between 1977 and 1981), and 1345 in the older cohort (aged 18-24 years at baseline, born between 1970 and 1977). Noteworthy changes in socio-demographic characteristics from baseline to second follow-up were found only for school/employment status (t2: secondary school: 13\%, employed: $36 \%$ ) and living arrangements (t2: with parents: 40\%; with partner: $23 \%$ ). There was no selective attrition due to age, gender or geographic distribution. A significantly high rate of drop-outs between $t 0$ and $\mathrm{t} 2$ was observed among subjects with nicotine dependence (OR: 1.6; 95\% CI: 1.2-2.0), dysthymia (OR: 2.7; 95\% CI: 1.6-4.4) and anorexia nervosa (OR: 3.7 ; 95\% CI: 1.3-10.4).

\subsection{Diagnostic assessment}

Face-to-face computer-assisted interviews were administered by clinical psychologists at baseline and at the two follow-ups. Diagnostic assessments ( $\mathrm{t} 0-\mathrm{t} 1-\mathrm{t} 2)$ were based on the Munich version of the Composite International Diagnostic Interview (M-CIDI, Wittchen and Pfister, 1997). At baseline, lifetime and past 12 month substance use, substance use disorders and other mental disorders were assessed according to DSM-IV criteria. In both follow-up investigations, substance use and diagnoses during the follow-up periods and for the previous 12 months were evaluated. The M-CIDI is an updated version of the World Health Organization s CIDI version 1.2 (WHO-CIDI; World Health Organization, 1992), which incorporates questions to cover DSM-IV (American Psychiatric Association, 1994) and ICD10 (World Health Organization, 1990) diagnostic criteria. The reliability and procedural validity of the M-CIDI has been established (Wittchen, 1994; Wittchen et al., 1998b; Lachner et al., 1998; Reed et al., 1998).

The assessment of illicit drug use, abuse and dependence has been comprehensively described elsewhere (Perkonigg et al., 1998). With regard to cannabis withdrawal, the M-CIDI assesses withdrawal symptoms for cannabis in the same way as for all other illegal substances. Participants were presented a list of 27 symptoms, among those craving, irritability, anxiety, sleep difficulty, abdominal cramping and others, and asked if they experienced any of these symptoms due to their cannabis use. In case of an affirmative answer they were asked if they had used the substance in order to avoid such symptoms.

\subsection{Data analysis}

Lifetime prevalence at baseline denotes the weighted rate of occurrence of any pattern of use or a specific diagnostic criterion in the total sample or in the subsamples. It covers the respondents' lifetime period prior to the assessment at baseline. Cumulative lifetime incidence was calculated by adding baseline, $\mathrm{t} 1$ and $\mathrm{t} 2$ follow- up incident cases (new outcomes during the follow-up period ( $\mathrm{t} 0$ to $\mathrm{t} 2$ ) among non-cases at baseline). In line with the WHO-CIDI conventions (World Health Organization, 1990; Lachner et al., 1998), four mutually exclusive patterns of drug use were considered (never; 1 time; $2-4$ times; 5 times and more). The question about use of drugs five times and more in lifetime is used within the M-CIDI as a gateway question to exclude purely experimental users.

Only for the individuals that used cannabis at least 5 times in their life the M-CIDI examines in detail (a) cannabis use frequency in the period (by year) in which the substance was used 
most frequently (peak time use: almost every day, 3-4 days per week, 1-2 days per week, 1-3 days per month, less than once a month) and (b) DSM-IV dependence criteria. Summarized use frequency categories are reported (monthly: 63 days per month, weekly: 1-2 days per week, daily: P3 days per week), choosing the latter cut-off because the "Risk of dependence among those using 3-4 days/week [...] was closer to that among daily users than among less frequent users" (Coffey et al., 2002). For subsequent analyses, the categories were merged into those with low frequency use (LFU), defined as participants who never consumed over two days in one week (monthly and weekly use), and high frequency use (HFU), defined as participants who consumed at least three days in one week in the peak cannabis use period (daily use).

For other illicit substances use was defined as cumulative use of any psychoactive drug other than cannabis, tobacco, alcohol or caffeine on five or more occasions in life ('concomitant use of other illicit drugs'). Analysis of the associations between illicit drug use and specific dependence criteria were also controlled for licit drug (alcohol and nicotine) dependence.

To account for design effects introduced by the use of weighted data, confidence intervals were estimated using the software package STATA (Stata Corporation, 2003) that applies the Huber-White sandwich matrix in this case (Royall, 1986). Cumulative lifetime incidence rates and logistic regressions are reported for cannabis use and specific dependence criteria, considering concomitant use of other illicit drugs as defined above. As development of substance dependence is known to be related to age and gender, all regressions were controlled for these two variables to approach a randomized distribution of age and gender in the studied sub-groups. If not indicated otherwise, differences between groups are based on comparisons of confidence intervals.

\section{Results}

\subsection{Lifetime prevalence of cannabis use by concomitant drug use status}

Table 1 presents the baseline lifetime prevalence of cannabis use frequency for the total sample and for two mutually exclusive subgroups of respondents with and without concomitant use of other illicit drugs. As shown in Table 1 at baseline one third $(34.2 \%)$ of the total sample used or had used cannabis. $16 \%$ were regular users, defined as use more than 5 times, $4.7 \%$ were daily users. At baseline the vast majority of cannabis users in the sample did not report the use of other illicit drugs. However, subjects with concomitant illicit drug use reveal considerably higher proportions of daily consumption $(2.2 \% / 4.5 \%=48.9 \%)$ as compared to users without concomitant use $(2.6 \% / 29.6 \%=8.8 \%)$.

\subsection{Cumulative incidence of cannabis use in the follow-up period by concomitant drug use status}

At follow-up t 2 a considerable increase of regular cannabis users can be noted (Table 2). The cumulative lifetime incidence for any cannabis use and for regular (5+) use is $46.8 \%$ and $29.9 \%$, respectively. The increases apply to both users with and without concomitant use of other illicit drugs. The total number of concomitant drug users in the sample had doubled. Table 2 also indicates considerably higher proportions of daily cannabis users in those with concomitant illicit drug use $(3.9 \% / 9.0 \%=43.3 \%)$ as compared to those without $(2.9 \%$ / $37.8 \%=7.7 \%)$. 
In summary, concomitant use of other illicit drugs is linked to a higher cannabis use frequency. To account for the confounding effect of cannabis use frequency on the following analyses of concomitant drug use and cannabis dependence criteria, the following analyses were carried out separately for low (LFU) and high (HFU) frequency cannabis users.

\subsection{Cumulative incidence of cannabis dependence symptoms by concomitant drug use among lifetime cannabis users}

One third of all cannabis users met at least one DSMIV dependence criterion in their lifetime, $16.7 \%$ only one, $6.6 \%$ two and $11.2 \%$ three or more (Table 3 ). The most frequently reported symptoms were: withdrawal, tolerance, consumed more of the substance than intended ('loss of control') and continued to take cannabis despite a health problem probably caused by the drug. Psychological problems played a more important role for the last criterion than physical problems.

The table also informs about the frequency of dependence symptoms by cannabis use frequency and concomitant use of other illicit drugs. Fairly irrespective of concomitant illicit drug use, LFU subjects $(\mathrm{N}=566)$ had overall a low probability of experiencing any, as well as two or three dependence criteria. Most frequent were withdrawal, loss of control, use despite a health problem and tolerance.

A considerably higher probability of dependence criteria resulted for HFU subjects. In addition, HFUs revealed some differences in the respective symptom pattern of those with and without concomitant illegal drug use: Concomitant drug users more often experienced psychological problems due to cannabis, and endorsed 'use despite health problems' more frequently. Next frequent criteria were withdrawal and tolerance. In contrast to LFUs, time excess obtaining/recovering played a major role and was one of the most frequent criteria in HFU subjects.

\subsection{Dependence symptoms among those with full-threshold cannabis dependence}

Subjects with a diagnosis of DSM-IV cannabis dependence most frequently reported the following specific 12-month dependence criteria: withdrawal $(90.6 \%)$, tolerance $(83.0 \%)$, continued use despite a health problem $(72.2 \%)$ and time excess obtaining/recovering (65.1\%). Thus, subjects fulfilling a diagnosis of cannabis dependence reported a similar pattern of dependence criteria as reported for HFUs in Table 3.

There were several noteworthy differences in the patterns of dependence symptoms between dependent subjects with and without concomitant drug use. 1 These differences were associated with a considerably higher total number of criteria met by the concomitant use group. To check for differences of means, the number of criteria were transformed with a Box-Cox-transformation to approximate a normal curve of distribution (Chen, 1995). A linear regression controlled for sex and age estimated the association between concomitant use and the number of criteria. A significant difference was found between the two groups regarding the mean of criteria met (Wald $F(1,52)=0.741, p=0.040$ ). Among persons with a fullthreshold cannabis dependence those with concomitant drug use met more lifetime cannabis dependence criteria than those without concomitant use (on the original scale: mean without: 4.2, SD: 1.3; mean with: 4.9, SD: 1.2).

\subsection{Degree of dependence symptoms in cannabis users attributable to the concomitant use of} other drugs 
For LFU subjects no association between concomitant use and dependence criteria was found. HFU concomitant users were at a higher risk to continue their cannabis use despite a health problem compared to pure cannabis users. This higher risk was attributable to 'use despite a psychological problem' in particular, because concomitant use was associated with the existence of a psychological problem due to cannabis. Concomitant HFUs had a lower risk to perceive loss of control over their cannabis use than HFUs without concomitant illegal drug use. Neither in LFUs nor in HFUs concomitant use of illicit substances was associated with the development of a certain number of dependence criteria or a full-blown dependence syndrome.

To examine whether the increased risk of cannabis dependence symptoms might be due to the existence of a dependence syndrome of nicotine or alcohol, the logistic model presented in Table 4 was rerun by controlling for nicotine or alcohol dependence. The associations and confidence intervals remained unchanged, and the significant odds ratios changed from 0.4 to 0.3 ('loss of control' in HFUs) and from 3.1 to 2.6 ('use despite health problem' in HFUs). This suggests that licit substance dependence does not affect the risk of cannabis dependence symptoms.

\section{Discussion}

The core findings of this paper are: first, a substantial proportion of young cannabis users develop DSM-IV dependence symptoms fairly independently of their use of other illicit substances as well as independently of nicotine dependence and alcohol dependence. Second, both, the risk of symptoms as well as the syndrome of dependence appear to be "dosedependent", occurring mainly in high frequency users as defined in this study.

To our knowledge this is the first epidemiological study among adolescents and young adults sampled in the community to examine and compare dependence symptoms in cannabis users with and without concomitant use of other illicit drugs. Compared to previous findings in clinical samples, such community samples are assumed to be less affected by biases such as helpseeking behavior, severity and demoralization, and thus can be expected to be of higher ecological validity. A further strength of the study is its longitudinal nature during the peak risk period of adolescence/young adulthood, possibly enhancing the value of findings for prevention and intervention.

Some limitations should be noted before discussing these findings: First, some attrition occurred from baseline to follow-up that might have had an effect on the data. A significantly high rate of drop-outs between $t 0$ and $t 2$ was observed among nicotine dependents. Additionally, 102 participants of the study did not want to answer to questions about illicit drug use at one or more of the assessments. This potential selective attrition, particularly in relation to nicotine, might have resulted in the description of a more favorable pattern of cannabis use and dependence. Second, diagnoses at baseline were retrospective and, therefore, subject to possible recall problems or biases, which might be accentuated by potential adverse effects of cannabis on memory performance. Finally, it must be highlighted that the validity of specific DSM-IV dependence criteria in general and that of specific CIDI items in particular, is still controversially discussed (e.g., Torrens et al., 2004; Cottler et al., 1997; Hasin et al., 1997; Nelson et al., 1999; Pull et al., 1997; Reed et al., 1998; Üstün et al., 1997; Wittchen, 1994). The inherent problems of reliability and validity in assessment tools need to be acknowledged and the continued need to resolve these critical issues remains of core importance for improved future research in this domain. 
With these limitations in mind, it should be noted that dependence symptoms are frequent among cannabis users: One third of cannabis users aged 17-28 years met criteria for at least one dependence symptom in their lifetime, and the number of dependence symptoms increased by frequency of use, suggesting some dose-response relationship. It should be highlighted that the patterns of dependence symptoms are similar across all use frequency groups, irrespective of concomitant use of other illegal and legal drugs as well as frequency of use.

Withdrawal was the most frequently reported dependence symptom even among low frequency users who did not use other illicit drugs. Other frequent dependence criteria were (in decreasing order by frequency): tolerance, loss of control and continued cannabis use despite a health problem. Concomitant use of other illicit drugs was not consistently associated with increased rates of specific dependence symptoms or their number.

The design features of our study make it difficult to directly compare our findings with the small number of previous studies addressing similar questions. However, our range and frequency of dependence symptoms are quite similar to those reported in an Australian sample of adult cannabis users (over 18 years) studied by Swift and colleagues (Swift et al., 2001). Participants in this study reported 12-month prevalent DSM-IV dependence symptoms as follows: desire to control use (37\%), withdrawal (30\%), tolerance $(22 \%)$, loss of control $(19 \%)$, time excess obtaining/recovering (9\%), continued use despite health problems $(9 \%)$ and $2 \%$ giving-up important activities. According to this, withdrawal and tolerance played a similar important role as in our group of high frequency users. Coffey and colleagues (Coffey et al., 2002) present 12-month prevalences on a representative sample of young adults (20-21 years) in Australia, using methods that are similar our study. They show some minor differences in symptom ranking compared to our data, and a considerably higher symptom occurrence in the Australian sample. These differences may be explained by the fact that the Australian data are based on a sample with current (last 12 months) and more frequent (at least weekly) cannabis use compared to frequency of use patterns in our sample. Different THCcontent in Australian marijuana, differences in dosing and route of administration and bio-availability could also explain these higher rates.

The present study adds to the previous findings epidemiological data supporting the validity and clinical relevance of the cannabis withdrawal criterion. The high prevalence of withdrawal irrespective of the use of other substances supports the concept of a cannabisspecific syndrome that can "not be explained better by another condition or disorder" (Smith, 2002 , p. 625). The fact that $8 \%$ of low frequency users and $46 \%$ of high frequency users with no illicit drug use report withdrawal, and a further $21 \%$ of the HFUs using the substance to avoid adverse effects, can be interpreted as signaling a considerable risk for future progression into dependence.

To conclude, we could show that a substantial proportion of young cannabis users in the general population experience dependence symptoms in their life, including the more "physiological" criteria tolerance and withdrawal. Unlike other studies we could rule out the influence of other illegal psychoactive substances on the development of dependence by separately examining subjects who only used cannabis and subjects with concomitant illegal drug use. We could also exclude the possibility that our findings are mediated by comorbid nicotine dependence and alcohol dependence. These findings are by and large consistent with attempts to develop cannabis-specific preventive and therapeutic programs. 
Table 1

Baseline ( $\left.t_{0}\right)$ lifetime prevalence of cannabis use by freq wency pattem and concomitant we of other illicit substances ${ }^{2}(N=2446)$

\begin{tabular}{|c|c|c|c|c|c|c|c|c|c|}
\hline \multirow[t]{2}{*}{ Cannabis we frequency } & \multicolumn{3}{|c|}{$\begin{array}{l}\text { Baseline cannabis use without } \\
\text { concomitant illicit drug use by } \\
\text { freq wency pattem }\end{array}$} & \multicolumn{3}{|c|}{$\begin{array}{l}\text { Baseline cannabis use with } \\
\text { conconitant illicit drug use by } \\
\text { frequency pattern }\end{array}$} & \multicolumn{3}{|c|}{ Total } \\
\hline & $N$ & $\% \mathrm{w}$ & $99 \% \mathrm{CI}$ & $N$ & $\% w$ & $95 \%$ C & $N$ & $\% \mathrm{w}$ & $99 \% \mathrm{CI}$ \\
\hline Any use & 638 & 29.6 & $(27.6-31.8)$ & 85 & 4.5 & $(3.6-5.7)$ & 723 & 34,2 & $(32.0-36.4)$ \\
\hline One-time use & 150 & 6.6 & $(5.5-7.9)$ & 6 & 0.4 & $(0.1-0.9)$ & 156 & 7.0 & $(5.8-8.3)$ \\
\hline 2-4 times use & 228 & 10.2 & $(8.9-11.7)$ & 17 & 1.1 & $(0.6-1.8)$ & 245 & 11.2 & $(9.8-12.8)$ \\
\hline $5+$ times use & 260 & 129 & $(11.3-14.6)$ & 62 & 3.1 & $(2.3-4.1)$ & 322 & 16.0 & $(12.3-20.7)$ \\
\hline Monthly & 156 & 8.1 & $(6.8-9.6)$ & 7 & 0.4 & $(0.1-0.9)$ & 163 & 8.5 & $(6.7-10.7)$ \\
\hline Weekly ${ }^{e}$ & 47 & 2.2 & $(1.6-3.0)$ & 11 & 0.6 & $(0.2-1.1)$ & 58 & 2.8 & $(2,0-3.7)$ \\
\hline Daily ${ }^{f^{\prime}}$ & 57 & 2.6 & $(1.9-3.4)$ & 44 & 2.2 & $(1.5-3.0)$ & 101 & 4.7 & $(3.5-6.4)$ \\
\hline
\end{tabular}

$\% \mathrm{w}=$ weighted percent.

a Five times and more; lifetime prevalence at $t_{0}$ over all illicit substances.

beak time use: $\$ 3$ days a month.

Peak time use: 1-2 days a week.

${ }^{d}$ Peak time use: $\$ 3$ days a week.

Table 2

Follow-up $\left(t_{2}\right)$ cumulative lifet ime incidence of cannabis use by frequency pattern and concomitant use of other illicit substances ${ }^{3}(N=2446)$

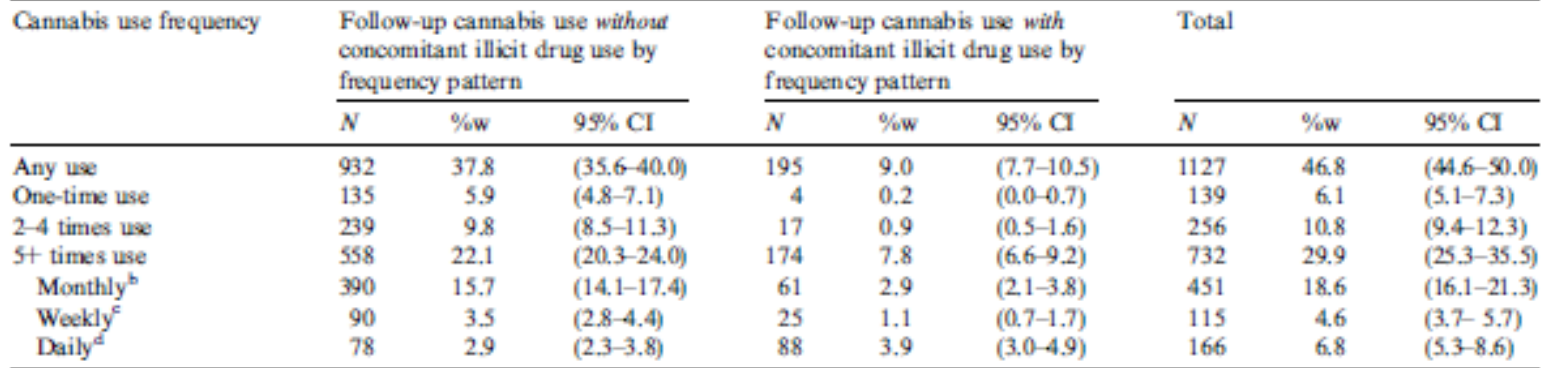

$\%$ weighted percent.

${ }^{a}$ Five times and more; cumulative lifetime incidence at $t_{2}$ over all illicit substances.

"Peak time use: $\leqslant 3$ days a month.

c Peak time use: 1-2 days a week.

'Peak time use: $\$ 3$ days a week.

Talie 3

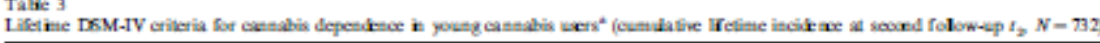

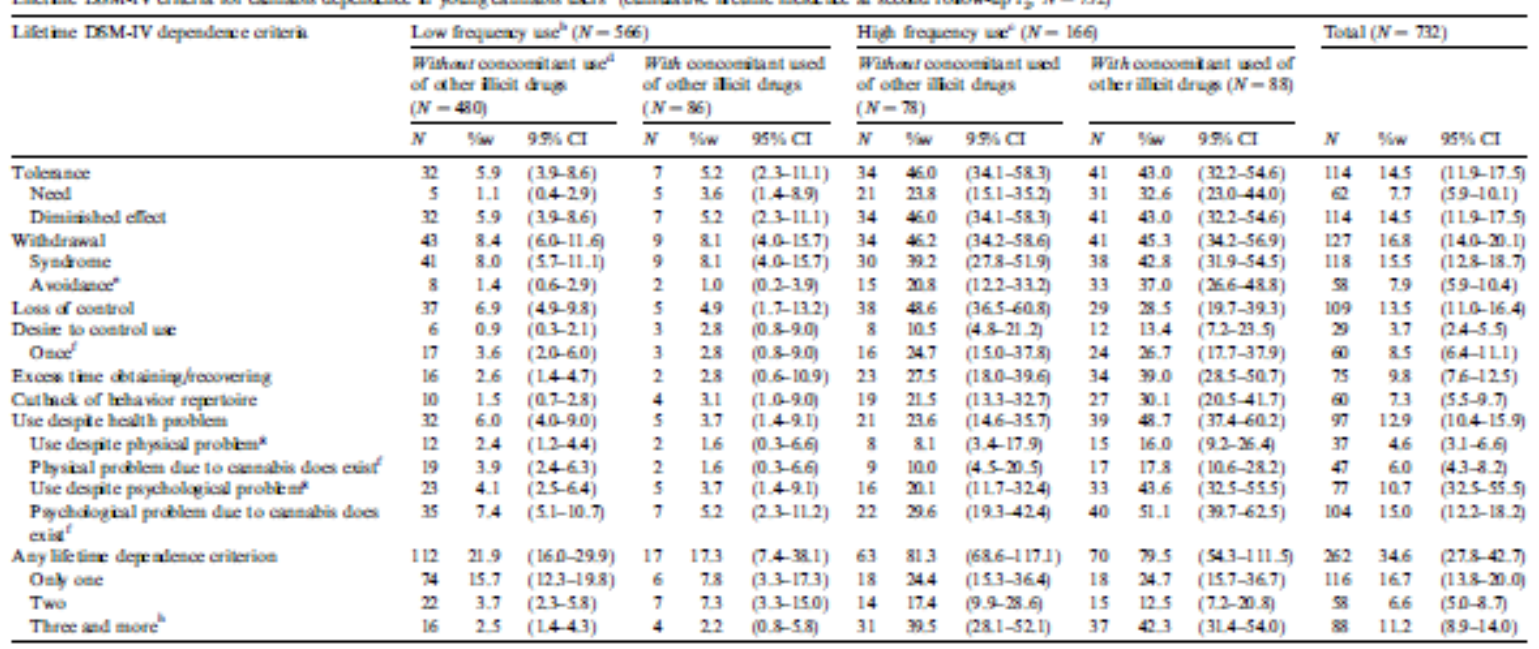

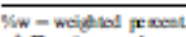

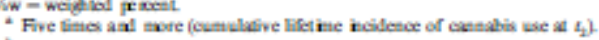

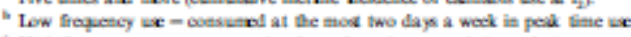

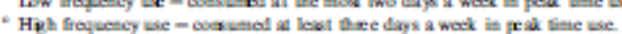

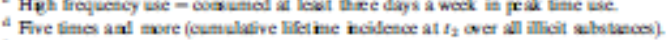

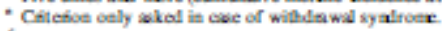

Simlrobala cellerion.

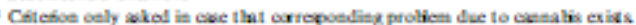

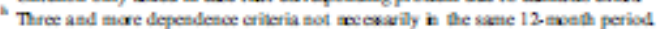


Table 4

Risk of lifetime DSM-IV cannabis dependence criteria for young cannabis ${ }^{a}$ users conditional to concomitant ${ }^{b}$ use of other illicit substances $(N=732)$

\begin{tabular}{|c|c|c|c|c|c|c|c|c|}
\hline \multirow[t]{2}{*}{ DSM-IV lifetime dependence criteria } & \multicolumn{4}{|c|}{$\begin{array}{l}\text { Low frequency use with versus withoud } \\
\text { concomitant illicit drug use }(N=566)\end{array}$} & \multicolumn{4}{|c|}{$\begin{array}{l}\text { High frequency used with versus withoud } \\
\text { concomitant illicit drug use }(N=166)\end{array}$} \\
\hline & $\% w^{e}$ Without & $\% \mathrm{w}^{f}$ With & OR & $99 \% \mathrm{CI}$ & $\% \mathrm{w}^{f}$ Without & $\% \mathbb{N}^{f}$ With & OR & $95 \% \mathrm{CI}$ \\
\hline Tolerance & 5.9 & 5.2 & 1.0 & $(0.3-2.6)$ & 46.0 & 43.0 & 1.0 & $(0.4-2.1)$ \\
\hline Diminished effect & 5.9 & 5.2 & 1.0 & $(0.3-2.6)$ & 46,0 & 43.0 & 1.0 & $(0,4-2,1)$ \\
\hline Withd rawal & 8.4 & 8.1 & 1.0 & $(0.4-2.4)$ & 46.2 & 45.3 & 1.0 & $(0.5-2.1)$ \\
\hline Syndrome & 8.0 & 8.1 & 1.1 & $(0.4-2.6)$ & 39.2 & 42.8 & 1.2 & $(0.5-2.5)$ \\
\hline Desire to control use & 0.9 & 2.8 & 3.6 & $(0.7-16.7)$ & 10.5 & 13.4 & 1.4 & $(0.4-4.2)$ \\
\hline Once ${ }^{h}$ & 3.6 & 2.8 & 0.8 & $(0.1-3.2)$ & 24.7 & 26.7 & 1.0 & $(0.4-2.4)$ \\
\hline Excess time obtaining/recovering & 2.6 & 2.8 & 1.1 & $(0.2-5.4)$ & 27.5 & 39.0 & 1.8 & $(0.8-3.7)$ \\
\hline Cutback of behavior repertoire & 1.5 & 3.1 & 2.3 & $(0.6-8.5)$ & 21.5 & 30.1 & 1.8 & $(0.8-3.9)$ \\
\hline Use despite heal th problem & 6.0 & 3.7 & 0.6 & $(0.2-1.8)$ & 23.6 & 48.7 & $3.1^{\circ}$ & $(1.4-6.7)$ \\
\hline Use despite physical problem ${ }^{i}$ & 2.4 & 1.6 & 0.7 & $(0.1-3.6)$ & 8.1 & 16.0 & 2.5 & $(0.7-8.2)$ \\
\hline Any dependence criterion & 21.9 & 17.3 & 0.8 & $(0.4-1.6)$ & 81.3 & 79.5 & 1.0 & $(0.4-2.3)$ \\
\hline Only one & 15.7 & 7.8 & 0.4 & $(0.1-1.2)$ & 24.4 & 24.7 & 1.0 & $(0.4-2.2)$ \\
\hline Two & 3.7 & 7.3 & 2.4 & $(0.9-6.2)$ & 17.4 & 12.5 & 0.8 & $(0.3-2.1)$ \\
\hline Three and more & 2.5 & 2.2 & 1.0 & $(0.3-3.1)$ & 39.5 & 42.3 & 1.2 & $(0.5-2.5)$ \\
\hline
\end{tabular}

$\mathrm{OR}=$ odds ratio from logistic regression, adjusted for sex and age.

${ }^{a}$ Five times and more (cumulative lifetime incidence of cannabis use at $t_{2}$ ).

bive times and more (cumulative lifetime incidence at $t_{2}$ over all illicit substances).

${ }^{c}$ Low frequency use $=$ consumed at the most two days a week in peak time use.

${ }^{d}$ High frequency use = consumed at least three days a woek in peak time use.

" Weighted percent without regular use of other illicit substances.

${ }^{f}$ Weighted percent with regular use of other illicit substances.

${ }^{g}$ Criterion only asked in case of withd rawal syndrome.

"Subthreshold criterion.

i Criterion only asked in case that problem exists.

j Three and more dependence criteria not necessarily in the same 12-month period.

$p<0.05$.

\section{Conflict of interest}

All authors declare that they do not have any conflict of interest.

\section{Acknowledgements}

This work is part of the Early Developmental Stages of Psychopathology (EDSP) Study and is funded by the German Ministry of Research and Technology, project nos. 01 EB 9405/6, 01 EB 9901/6, 01 EB 140 and 01 EB 0440. Principal investigators are Dr. Hans-Ulrich Wittchen and Dr. Roselind Lieb. Current or former staff members of the EDSP group are Dr. Kirsten von Sydow, Dr. Gabriele Lachner, Dr. Axel Perkonigg, Dr. Peter Schuster, Dipl.-Stat. Michael Höfler, Mag. phil. Esther Beloch, Dr.Martina Fuetsch, Dipl.-Psych. Elzbieta Garczynski, Dr. Barbara Isensee, Dr. Marianne Mastaler, Dr. Chris Nelson, Dipl.-Psych. Agnes Nocon, Dipl.-Inf. Hildegard Pfister, Dr. Victoria Reed, Dipl.Psych. Andrea Schreier, Dipl.-Soz. Barbara Spiegel, Dipl.-Psych. Dilek Türk, Dipl.-Psych. Antonia Vossen, Dr. Ursula Wunderlich and Dr. Petra Zimmermann. Scientific advisors are Dr. Jules Angst (Zurich), Dr. Jürgen Margraf (Basel), Dr. Günther Esser (Potsdam), Dr. Kathleen Merikangas (NIMH, Bethesda) and Dr. Ron Kessler (Harvard, Boston). We thank Evelyn Kühne, Holmfridur Vilhjalmsdottir and Dzifa Vode for their help in proofreading this manuscript and the anonymous reviewers for their constructive suggestions to improve the paper. Our special thanks go to the participants of this study. 


\section{References}

- American Psychiatric Association. Diagnostic and statistical manual of mental disorders. 4th ed. Washington (DC): American Psychiatric Association; 1994.

- Anthony JC, Helzer JE. Syndromes of drug abuse and dependence. In: Robins LN, Regier DA, editors. Psychiatric disorders in America: The Epidemiologic Catchment Area study. New York: The Free Press; 1991. p. 116-54.

- Anthony JC, Trinkoff AM. United States epidemiologic data on drug use and abuse: How are they relevant to testing abuse liability of drugs? In: Fischman MW, Mello NK, editors. NIDA Research Monograph Series, vol. 92. Rockville (MD): National Institute on Drug Abuse; 1989. p. 241-66.

- Anthony JC, Warner LA, Kessler RC. Comparative epidemiology of dependence on tobacco, alcohol, controlled substances, and inhalants: basic findings from the National Comorbidity Survey. Experimental and Clinical Psychopharmacology 1994;2(3):244-68.

- Australian Institute of Health and Welfare. 1998 National drug strategy household survey: first results [online], 1999. Available from:

http://www.aihw.gov.au/publications/health/ndshs98/ndshs98.pdf [Accessed 14 December 2004].

- Chen H. Tests following transformations. Annals of Statistics 1995;23(5):1587-93.

- Chung T, Colby SM, O'Leary TA, Barnett NP, Monti PM. Screening for cannabis use disorders in an adolescent emergency department sample. Drug and Alcohol Dependence 2003;70(2):177-86.

- Coffey C, Carlin JB, Degenhardt L, Lynskey MT, Sanci L, Patton GC. Cannabis dependence in young adults: an Australian population study. Addiction 2002;97(2):187-94.

- Coffey C, Carlin JB, Lynskey MT, Li N, Patton GC. Adolescent precursors of cannabis dependence: findings from the Victorian Adolescent Health Cohort Study. British Journal of

- Psychiatry 2003;182:330-6.

- Cottler LB, Grant BF, Blaine J, Mavreas V, Pull CB, Hasin D, et al. Concordance of DSM-IV alcohol and drug use disorder criteria and diagnoses as measured by AUDADIS-ADR, CIDI and SCAN. Drug and Alcohol Dependence 1997;47(3):195-205.

- Crowley TJ, Macdonald MJ, Whitmore EA, Mikulich SK. Cannabis dependence, withdrawal, and reinforcing effects among adolescents with conduct symptoms and substance use disorders. Drug and Alcohol Dependence 1998;50(1):27-37.

- de Graaf R. (rgraaf@trimbos.nl). (25 Feb 2004). RE: Cannabis dependence; e-mail to Nocon A. (nocon@mpipsykl.mpg.de).

- Degenhardt L, Lynskey MT, Hall W. Cohort trends in the age of initiation of drug use in Australia. Australian and New Zealand Journal of Public Health 2000;24(4):421-6.

- Dennis M, Babor TF, Roebuck MC, Donaldson J. Changing the focus: the case for recognizing and treating cannabis use disorders. Addiction 2002;97(Suppl 1):4-15.

- European Monitoring Centre for Drugs and Drug Addiction. Annual report 2003: The state of the drugs problem in the European Union and Norway. Luxembourg: Office for Official Publications of the European Communities, 2003.

- Fergusson DM, Horwood LJ. Cannabis use and dependence in a New Zealand birth cohort. New Zealand Medical Journal 2000;113(1109):156-8.

- Hall W, Solowij N. Adverse effects of cannabis. Lancet 1998;352(9140):1611-6.

- Hall W, Solowij N, Lemon J. The health and psychological consequences of cannabis use. National Drug Strategy Monograph, vol. 25. Canberra: Australian Government Publication Services; 1994.

- Hasin D, Grant BF, Cottler LB, Blaine J, Towle L, Üstün BT, et al. Nosological comparisons of alcohol and drug diagnoses: a multisite, multi-instrument international study. Drug and Alcohol Dependence 1997;47(3):217-26.

- Lachner G, Wittchen HU, Perkonigg A, Holly A, Schuster P, Wunderlich U, et al. Structure, content and reliability of the Munich-Composite International Diagnostic Interview (M-CIDI) substance use sections. European Addiction Research 1998;4(1-2): 28-41. 
- Lieb R, Schuster P, Pfister H, Fuetsch M, Höfler M, Isensee B, et al. Epidemiology of substance use, abuse and dependence among adolescents and young adults: the prospectivelongitudinal EDSPstudy. Sucht 2000;46(1):18-31.

- Muller S, Gmel G. Veränderungen des Einstiegsalters in den Cannabiskonsum: Ergebnisse der zweiten Schweizer Gesundheitsbefragung 1997 [Changes in the age of onset of cannabis use: results of the 2nd Swiss Health Survey 1997]. Sozial- und Praventivmedizin 2002;47(1):1423.

- Nelson CB, Rehm J,Üstün BT, Grant B, Chatterji S. Factor structures for DSM-IV substance disorder criteria endorsed by alcohol, cannabis, cocaine and opiate users: results from the WHO reliability and validity study. Addiction 1999;94(6):843-55.

- Perkonigg A, Beloch E, Garczynski E, Nelson CB, Pfister H, Wittchen HU. Prävalenz von Drogenmissbrauch und -abhängigkeit bei Jugendlichen und jungen Erwachsenen: Gebrauch, Diagnosen und Auftreten erster Missbrauchs- und Abhängigkeitsmerkmale [Prevalence of drug abuse and dependence: use of illicit substances, diagnosis and onset of first abuse and dependence symptoms]. Zeitschrift für Klinische Psychologie 1997;26(4):247-57.

- Perkonigg A, Lieb R, Höfler M, Schuster P, Sonntag H, Wittchen HU. Patterns of cannabis use, abuse and dependence over time: incidence, progression and stability in a sample of 1228 adolescents. Addiction 1999;94(11):1663-78.

- Perkonigg A, Lieb R, Wittchen HU. Prevalence of use, abuse and dependence of illicit drugs among adolescents and young adults in a community sample. European Addiction Research 1998;4(1-2):58-66.

- Poulton RG, Brooke M, Moffitt TE, Stanton WR, Silva PA. Prevalence and correlates of cannabis use and dependence in young New Zealanders. New Zealand Medical Journal 1997;110(1039):68-70.

- Pull CB, Saunders JB, Mavreas V, Cottler LB, Grant BF, Hasin DS, et al. Concordance between ICD-10 alcohol and drug use disorder criteria and diagnoses as measured by the AUDADIS-ADR, CIDI and SCAN: results of a cross-national study. Drug and Alcohol Dependence 1997;47(3):207-16.

- Reed V, Gander F, Pfister H, Steiger A, Sonntag H, Trenkwalder C, et al. To what degree the Composite International Diagnostic Interview (CIDI) correctly identifies DSM-IV disorders? Testing validity issues in a clinical sample. International Journal of Methods in Psychiatric Research 1998;7(3):142-55.

- Royall RM. Model robust confidence intervals using maximum likelihood estimators. International Statistical Review 1986;54(2):221-6.

- Smith NT.Areview of the published literature into cannabis withdrawal symptoms in human users. Addiction 2002;97(6):621-32. Stata Corporation. Stata statistical software: release 8.2. College Station (TX): Stata Corporation; 2003.

- Swift W, Hall W, Copeland J. One year follow-up of cannabis dependence among long-term users in Sydney, Australia. Drug and Alcohol Dependence 2000;59(3):309-18.

- Swift W, Hall W, Teesson M. Characteristics of DSM-IV and ICD-10 cannabis dependence among Australian adults: results from the National Survey of Mental Health and Wellbeing. Drug and Alcohol Dependence 2001;63(2):147-53.

- Sydow K von, Lieb R, Pfister H, Höfler M, Sonntag H, Wittchen HU. The natural course of cannabis use, abuse and dependence over four years: a longitudinal community study of adolescents and young adults. Drug and Alcohol Dependence 2001;64(3):347-61.

- Sydow K von, Lieb R, Pfister H, Höfler M, Wittchen HU. What predicts incident use of cannabis and progression to abuse and dependence? A 4-year prospective examination of risk factors in a community sample of adolescents and young adults. Drug and Alcohol Dependence 2002;68(1):49-64.

- Torrens M, Serrano D, Astals M, Pérez-Domínguez G, Martín-Santos R. Diagnosing psychiatric comorbidity in substance abusers. Validity of the Spanish version of the Psychiatric Research Interview for Substance and Mental Disorders (PRISM-IV) and the Structured Clinical Interview for DSM-IV (SCID-IV). American Journal of Psychiatry 2004;161:1231-7. 
- Üstün BT, Compton WM, Mager D, Babor TF, Baiyewu O, Chatterji S, et al. WHO Study on the reliability and validity of the alcohol and drug use disorder instruments: overview of methods and results. Drug and Alcohol Dependence 1997;47(3):161-9.

- Winters KC, Latimer W, Stinchfield RD. The DSM-IV criteria for adolescent alcohol and cannabis use disorders. Journal of Studies on Alcohol 1999;60(3):337-44.

- Wittchen HU. Reliability and validity studies of the WHO-Composite International Diagnostic Interview (CIDI): a critical review. Journal of Psychiatric Research 1994;28(1):57-84.

- Wittchen HU. Ergänzung II zum Schlussbericht. Zusatzsurvey Psychische Störungen’, (Bundesgesundheitssurvey 98): Häufigkeit, psychosoziale Beeinträchtigungen und Zusammenhänge mit körperlichen Erkrankungen, 2000.

- Wittchen HU, Jacobi F. Die Versorgungssituation psychischer Störungen in Deutschland. Eine klinisch-epidemiologische Abschätzung des Bundes-Gesundheitssurveys 1998 [Met and unmet needs for intervention. Clinical-epidemiological estimations for mental disorders in the German Health Interview and Examination Survey Supplement]. Bundesgesundheitsbl Gesundheitsforsch - Gesundheitsschutz 2004;44:993-1000.

- Wittchen HU, Pfister H. DIA-X-Interviews: Manual für Screening-Verfahren und Interview; Interviewheft Längsschnittuntersuchung (DIA-X 12 Monate); Ergänzungsheft (DIA-X 12 Monate); PC-Programm zur Durchführung des Interviews (Längs- und Querschnittsuntersuchung); Auswertungsprogramm. Frankfurt: Swets \& Zeitlinger; 1997.

- Wittchen HU, Höfler M, Perkonigg A, Sonntag H, Lieb R. Wie stabil sind Drogenkonsum und das Auftreten klinisch-diagnostisch relevanter Missbrauchs- und Abhängigkeitsstadien bei Jugendlichen? Eine epidemiologische Studie am Beispiel von Cannabis [Stability of cannabis use, abuse and dependence patterns in a community sample of adolescents]. Kindheit und Entwicklung 1998a;7(4):188-98.

- Wittchen HU, Lachner G, Wunderlich U, Pfister H. Test-retest reliability of the computerized DSM-IV version of the Munich Composite International Diagnostic Interview (M-CIDI). Social Psychiatry and Psychiatric Epidemiology 1998b;33(11):568-78.

- Wittchen HU, Nelson CB, Lachner G. Prevalence of mental disorders and psychosocial impairments in adolescents and young adults. Psychological Medicine 1998c;28(1):109-26.

- Wittchen HU, Perkonigg A, Lachner G, Nelson CB. Early developmental stages of psychopathology study (EDSP): objectives and design. European Addiction Research 1998d;4(1-2):18-27.

- World Health Organization. The ICD-10 classification of mental and behavioral disorders. Geneva: World Health Organization; 1990.

- World Health Organization. Composite International Diagnostic Interview (CIDI): (a) CIDIinterview (version 1.0), (b) CIDI-user manual, (c) CIDI-training manual, (d) CIDI-computer programs. Geneva: World Health Organization; 1992.

- Young SE, Corley RP, Stallings MC, Rhee SH, Crowley TJ, Hewitt JK. Substance use, abuse and dependence in adolescence: prevalence, symptom profiles and correlates. Drug and Alcohol Dependence 2002;68(3):309-22.

- Zoccolillo M, Vitaro F, Tremblay RE. Problem drug and alcohol use in a community sample of adolescents. Journal of the American Academy of Child and Adolescent Psychiatry 1999;38(7):900-7. 